\title{
At 2,14-24: o cumprimento da promessa
}

\author{
Orientador: Prof. Leonardo Agostini Fernandes
}

Pesquisadora: Rita Mara de Aguilar Pereira

Fonte: $\mathrm{CNPq}$

Introdução

Esta pesquisa estuda a fundamentação bíblica que dá sustentabilidade ao surgimento de novos movimentos religiosos de cunho pentencostal, tanto na Igreja Católica, como também fora dela. Encontra-se na base bíblica desse fenômeno, principalmente, os textos de J1 3,1-5; Jo 16,5-15 e At 2,1-41.

Na primeira etapa do trabalho, estudou-se o texto de J1 3,1-5: A Promessa da efusão do Espírito, pelo qual se verificou o caráter escatológico da profecia. Nesta segunda etapa do trabalho, volta-se para o texto de At 2,14-24, que narra a citação do texto do profeta Joel no discurso do apóstolo Pedro no dia de Pentecostes. A motivação para a sua realização está na análise do texto de Atos e na leitura que o apóstolo faz dos acontecimentos de Pentecostes como cumprimento da promessa de Joel. Para a compreensão mais profunda desse estudo, se dará também a aplicação dos métodos de análise exegética.

\section{Objetivos}

O objetivo geral será estudar e aprofundar o sentido das palavras de Pedro no texto do discurso e sua citação do texto de Jl 3,1-5. Os objetivos particulares continuam praticamente os mesmos do trabalho anterior, visto que este é a complementação do mesmo: a) Buscar uma compreensão correta do sentido da leitura que Lucas sobre os acontecimentos do evento Pentecostes como cumprimento da promessa; b) Estimular a reflexão acadêmica, a fim de favorecer a compreensão de At 14-24 em nível pessoal e comunitário; c) Entender o sentido que At 2,14-24 quis atribuir ao texto de J1 3,1-5; d) encontrar, no texto de J1 3,1-5 e na sua releitura no livro dos Atos dos Apóstolos, uma fundamentação para o surgimento, crescimento e fortalecimento dos movimentos pentecostais, em especial a Renovação Carismática Católica. 